\title{
Red Listing can protect deep-sea biodiversity
}

To the Editor - Deep-sea hydrothermal vents were discovered only 40 years ago. We now know that around 600 of these auditorium-sized oases exist in the vast expanse of the ocean ${ }^{1,2}$, flourishing with unique life that we are nowhere close to fully understanding (Fig. 1). This lack of baseline biodiversity assessments creates an 'out of sight, out of mind' conservation dilemma for deep-sea biodiversity, which is threatened by surging interest in seafloor sulfide mining. We argue that the International Union for the Conservation of Nature (IUCN) Red List of Threatened Species - with formal goals to draw attention to threatened biodiversity and provide objective information to guide conservation actions and international policy $^{3,4}$ - is the ideal tool to make deep-sea species more visible.

The dynamic habitats and turnover of hydrothermal vent communities resulting from frequent eruptive and tectonic events at the fast-spreading East Pacific Rise have been used to suggest that hydrothermal vent ecosystems are naturally resilient to disturbance ${ }^{5}$. But we cannot assume such resilience also applies to other vents with different species and different geological and biological contexts ${ }^{1}$.

We suggest that a list of species endemic to each hydrothermal vent, and their respective Red List status, would serve as a proxy for the uniqueness of each site. This will not be easy to compile; a Red List assessment can only be based on the best available data at any time for any species, yet many deep-sea species are known from a small number of specimens or observations, may never have been observed alive, and have behaviours that are confounded by observer interference in a realm with no sunlight. However, a 'wait and see' approach, assuming all uncertainty will be resolved by future data, ignores the reality that

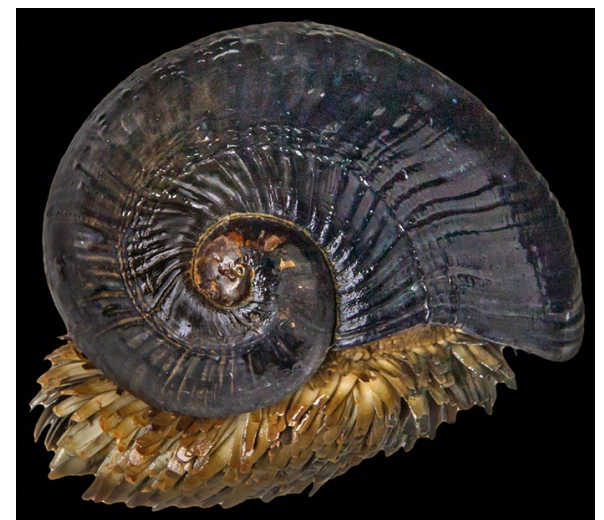

Fig. 1 | The scaly-foot snail. Chrysomallon squamiferum, also known as the sea pangolin, displays unique iron-infused scales. The species has recently been listed as 'Endangered' on the IUCN Red List. Credit: Chong Chen

anthropogenic disturbance is accelerating faster than scientific discovery.

A new addition to the IUCN Red List, the scaly-foot snail or sea pangolin (Chrysomallon squamiferum $)^{6}$, exemplifies how Red List criteria can be applied to organisms in these habitats. This species occurs at three sites at depths of 2,400 m$2,900 \mathrm{~m}$ and comprising a total area of around $0.02 \mathrm{~km}^{2}$ (equivalent to about two football fields). Two of the three sites are under mining exploration licenses ${ }^{7}$, and the species has little or no ability to recolonize from elsewhere in its range ${ }^{8}$. On the basis of the small number of locations in which it exists, and the potential for a future threat to suddenly drive the species much closer to extinction, the scaly-foot snail is now listed as 'Endangered'. Draft assessments have now been completed for 14 additional species that are endemic to hydrothermal vents in the Indian and Pacific Oceans, all of which are expected to be listed as 'Vulnerable', 'Endangered' or 'Critically Endangered'. In other situations, the IUCN Red List has been widely applied as a tool for business and financial decision-making ${ }^{9}$ as well as conservation. The listing of deepsea species represents a first step towards a global assessment for these habitats, and towards ensuring that deep-sea species have a seat at the table in discussions about managing the ocean floor.

Julia D. Sigwart (D)1, Chong Chen (D) 2*, Elin A. Thomas' ${ }^{1}$ A. Louise Allcock ${ }^{3}$, Monika Böhm ${ }^{4}$ and Mary Seddon ${ }^{5}$

${ }^{1}$ Queen's University Belfast, Marine Laboratory, Portaferry, Northern Ireland, UK. ${ }^{2} X-S T A R$, Japan Agency for Marine-Earth Science and Technology (JAMSTEC), Kanagawa, Japan. ${ }^{3}$ National University of Ireland, Galway, Galway, Ireland. ${ }^{4}$ Institute of Zoology, Zoological Society of London, London, UK. ${ }^{5}$ IUCN SSC Mollusc Specialist Group, Devon, UK. *e-mail:cchen@jamstec.go.jp

Published online: 22 July 2019

https://doi.org/10.1038/s41559-019-0930-2

References

1. Van Dover, C. L. et al. Mar. Policy 90, 20-28 (2018).

2. Beaulieu, S. E., Baker, E. T., German, C. R. \& Maffei, A. Geochem Geophys. Geosyst. 14, 4892-4905 (2013).

3. IUCN Red List Categories and Criteria: Version 3.1 (IUCN Species Survival Commission, 2001).

4. The IUCN Red List of Threatened Species. Version 2019-1 (IUCN, 2019); http://www.iucnredlist.org/

5. Gollner, S. et al. Mar. Environ. Res. 129, 76-101 (2017).

6. Sigwart, J., Chen, C. \& Thomas, E. A. Chrysomallon squamiferum. The IUCN Red List of Threatened Species (2019); https://www. iucnredlist.org/species/103636217/103636261

7. Sigwart, J. D., Chen, C. \& Marsh, L. Nautilus 131, 43-50 (2017).

8. Chen, C., Copley, J. T., Linse, K. \& Rogers, A. D. Org. Divers. Evol. 15, 663-670 (2015).

9. Bennun, L. et al. Conserv. Lett. 11, e12353 (2018).

Competing interests

All authors are unpaid members of the IUCN Species Survival Commission (SSC) Mollusc Specialist Group chaired by M.S. 